\title{
Importance of Early Screening and Diagnosis of Chronic Kidney Disease in Patients with Type 2 Diabetes
}

\author{
Neil S. Skolnik · Alyssa J. Style
}

Received: February 1, 2021 / Accepted: March 13, 2021 / Published online: April 29, 2021

(C) The Author(s) 2021

\begin{abstract}
It is estimated that one in ten people in the USA have diabetes. Approximately $40 \%$ of those with diabetes also develop chronic kidney disease (CKD), which in turn increases their risk of developing cardiovascular disease. Evidencebased recommendations for the treatment of patients with type 2 diabetes (T2D) and concomitant CKD are provided by several medical societies, including the American Diabetes Association (ADA), but in real life are only carried out in fewer than $50 \%$ of individuals for whom they are recommended. Screening for CKD is recommended using the spot urine albumin-to-creatinine ratio and estimated glomerular filtration rate in all patients with T2D at the time of diagnosis, and at least annually thereafter. Screening enables early CKD diagnosis, counseling, pharmacologic intervention and, when appropriate, referral to a nephrologist. The ADA guidelines recommend good glycemic and blood pressure control and the use of medications that are kidney protective. Medications shown to slow progression of CKD include renin-angiotensin system inhibitors, sodium-glucose cotransporter- 2 inhibitors, glucagon-like peptide 1 receptor agonists and, more recently, non-steroidal mineralocorticoid
\end{abstract}

N. S. Skolnik $(\bowtie) \cdot$ A. J. Style

Abington Family Medicine, Jenkintown, PA, USA

e-mail: nskolnik@comcast.net receptor antagonists. Novel agents with different mechanisms of action are also in development that have the potential to further slow or prevent disease progression when used with currently recommended therapies.

Keywords: Albuminuria; Diabetes mellitus, Type 2; Glomerular filtration rate; Glucagonlike peptide 1 receptor agonists; Renal insufficiency, Chronic; Renin-angiotensin system; $\quad$ Sodium-glucose cotransporter-2 inhibitors; UACR 


\section{Key Summary Points}

Evidence-based recommendations for the treatment of patients with chronic kidney disease (CKD) and type 2 diabetes (T2D) are currently followed in fewer than $50 \%$ of individuals.

Screening for CKD is recommended using spot urine albumin-to-creatinine ratio and estimated glomerular filtration rate in all patients with T2D at diagnosis, and at least annually thereafter.

Screening enables early CKD diagnosis, counseling, pharmacologic intervention and, when appropriate, referral to a nephrologist.

Medications shown to slow progression of CKD include renin-angiotensin system inhibitors, sodium-glucose cotransporter2 inhibitors, glucagon-like peptide 1 receptor agonists, and, more recently, non-steroidal mineralocorticoid receptor antagonists.

\section{DIGITAL FEATURES}

This article is published with digital features, including a summary slide to facilitate understanding of the article. To view digital features for this article go to https://doi.org/10.6084/ m9.figshare.14208032.

\section{INTRODUCTION}

Patients with diabetes mellitus are at increased risk for developing chronic kidney disease (CKD) $[1,2]$. In the USA, diabetic nephropathy is the leading cause of kidney failure [3]. The presence of concomitant CKD in patients with type 2 diabetes (T2D) is associated with significantly increased risks of cardiovascular disease (CVD), including myocardial infarction, ischemic stroke/transient ischemic attacks, and all-cause mortality, when compared with the risk in patients with T2D without CKD $[4,5]$. Therapies exist that can slow the progression of CKD in persons with diabetes; therefore, early detection and intervention for CKD is important.

In this review, we assess the burden of CKD in US patients with T2D and describe how clinicians can use early screening and diagnosis, together with guideline-recommended management strategies provided by the American Diabetes Association (ADA), to optimize patient outcomes. This article is based on previously conducted studies and does not contain any studies with human participants or animals performed by any of the authors.

\section{BURDEN OF CKD}

Current estimates suggest that approximately 463 million people globally have diabetes mellitus, and this number is projected to rise to an estimated 700 million by 2045 [6]. In 2018, approximately $10.5 \%$ of the US population had diabetes [7]. Up to $40 \%$ of patients with diabetes also develop CKD, which is associated with significant morbidity, deficits in quality of life, and increased healthcare burden [8-12]. Progression of CKD can lead to kidney failure (endstage kidney disease [ESKD]), with patients requiring either dialysis or a kidney transplant for survival. In 2015, 661,000 Americans had ESKD [10]; approximately $71 \%$ were receiving hemodialysis or peritoneal dialysis, and 29\% were living with a functioning kidney transplant. Of the individuals with ESKD, approximately $44-45 \%$ had diabetes listed as the primary cause of ESKD [11, 12]. Per-person costs for patients aged $>65$ years with CKD and diabetes are $51 \%$ higher than for patients with diabetes who do not have CKD [2]. Furthermore, health-related quality of life decreases as CKD progresses [9]. 


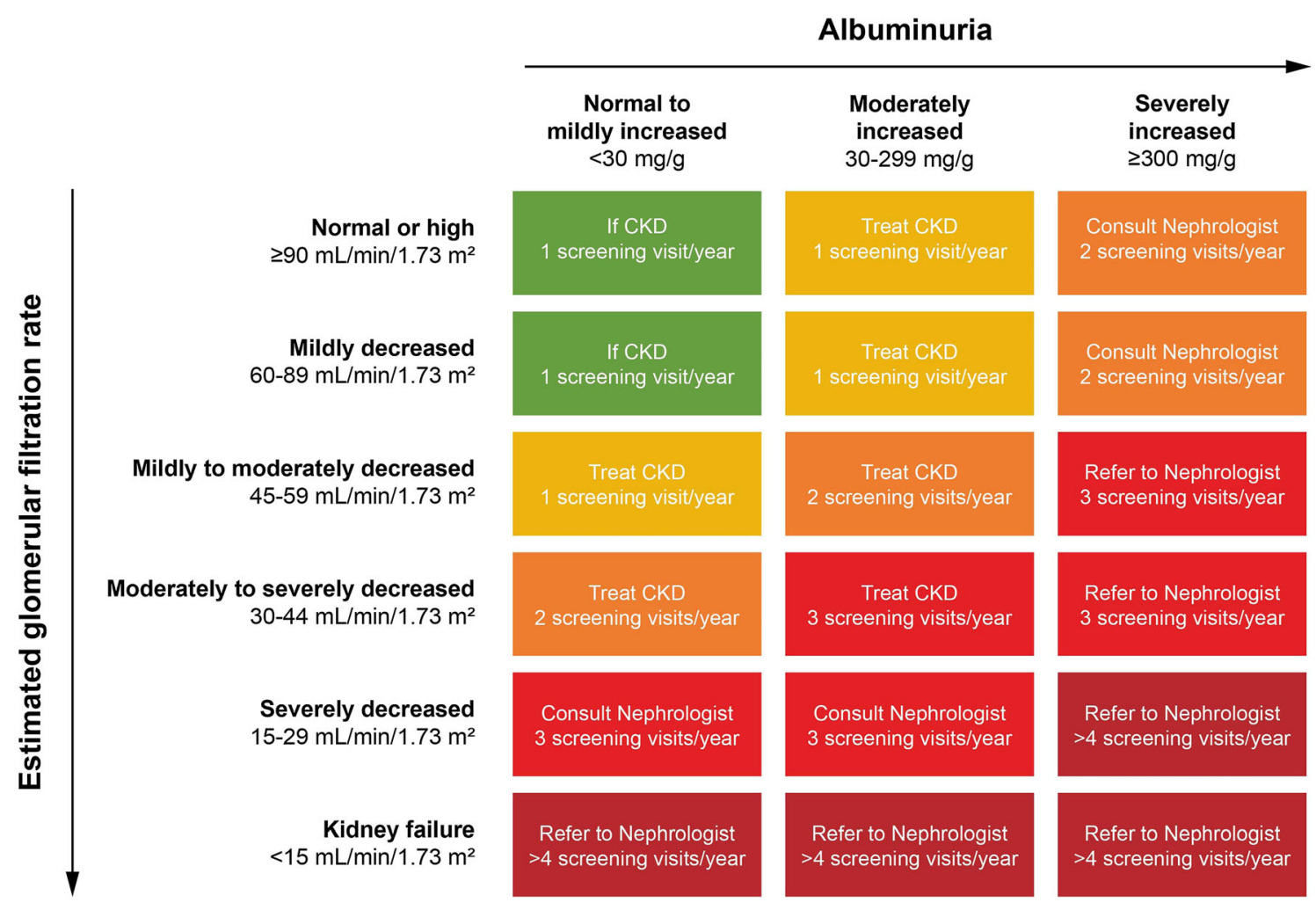

Fig. 1 Risk of CKD progression, frequency of visits, and referral to a nephrologist according to glomerular filtration rate (GFR) and albuminuria. The GFR and albuminuria grid depicts the risk of progression, morbidity, and mortality by color, from best (green) through yellow, orange, and red to worst (dark red). CKD Chronic kidney disease. Modified from Kidney Disease: Improving Global Outcomes (KDIGO) CKD Work Group [61], copyright 2013, with permission from Elsevier

therapy [14]. Of note, in 2013 the American College of Physicians made the recommendation that patients with T2D and CKD (stage 1-3) receiving an angiotensin-converting enzyme inhibitor (ACEi) or angiotensin II receptor blocker (ARB) did not need to undergo annual testing for proteinuria [15]. This recommendation has been retired, and therefore it is important that primary care providers (PCPs) take note of this change and adjust their practice accordingly. Based on the ADA guidelines, patients with stage 1-3 CKD should be screened between one and three times annually based on their level of albuminuria (Fig. 1) [14].

The preferred method for assessment of albuminuria is the UACR, measured in a random spot urine collection [14]. This method of assessment is easy to perform compared with a 24-h urine collection, which is inconvenient for 
Table 1 American Diabetes Association treatment goals and guidance [14]

\begin{tabular}{|c|c|}
\hline $\begin{array}{l}\text { Treatment } \\
\text { targets }\end{array}$ & ADA Guidance \\
\hline $\mathrm{A} 1 \mathrm{C}$ & $\begin{array}{l}\text { - A1C goal for many nonpregnant adults is }<7 \%(53 \mathrm{mmol} / \mathrm{mol}) \\
\text { - More stringent A1C goals (such as }<6.5 \%[48 \mathrm{mmol} / \mathrm{mol}]) \text { for some patients, but care should be } \\
\text { taken to avoid significant hypoglycemia or polypharmacy (e.g., in patients with a short duration of } \\
\text { diabetes, T2D treated with lifestyle or metformin only, long life expectancy, or no significant CVD) } \\
\text { - Less stringent A1C goals (e.g., }<8 \%[64 \mathrm{mmol} / \mathrm{mol}]) \text { may be appropriate for some patients (e.g., those } \\
\text { with a history of severe hypoglycemia, limited life expectancy, advanced micro- or macrovascular } \\
\text { complications, extensive comorbid conditions, or long-standing diabetes in whom the goal is difficult to } \\
\text { achieve) } \\
\text { - Reassess glycemic targets over time }\end{array}$ \\
\hline BP & $\begin{array}{l}\text { - } \mathrm{BP} \text { control should be optimized to reduce the risk or slow the progression of CKD } \\
\text { - } \mathrm{BP} \text { targets should be individualized through a shared decision-making process } \\
\text { - Patients with hypertension should, at a minimum, be treated to BP targets of }<140 / 90 \mathrm{mmHg} \text { to } \\
\text { reduce CVD mortality and slow CKD progression } \\
\text { - Lower BP targets (e.g., }<130 / 80 \mathrm{mmHg} \text { ) should be considered for some patients based on individual } \\
\text { anticipated benefits and risks (e.g., those with } \geq 300 \mathrm{mg} / \text { day albuminuria) }\end{array}$ \\
\hline
\end{tabular}

AIC Glycated hemoglobin, $A D A$ American Diabetes Association, $B P$ blood pressure, $C K D$ chronic kidney disease, $C V D$ cardiovascular disease, $T 2 D$ type 2 diabetes

patients and subject to incomplete collection [16]. Concurrent measurement of urinary creatinine ensures that variations in albumin concentration due to hydration levels do not confound the result. A positive diagnosis of increased urinary albumin excretion, defined as $\geq 30 \mathrm{mg} / \mathrm{g}$ albumin/creatinine, should only be made when two of three samples collected over a 3- to 6-month period exceed that threshold [14].

It is important to assess both the UACR and the eGFR because albuminuria can predict CKD risk earlier than a decrease in GFR; for example, the UACR can be moderately increased when the eGFR is still normal (Fig. 1) [14, 17]. The eGFR can also be high (eGFR $>90 \mathrm{~mL} / \mathrm{min} / 1.73$ $\mathrm{m}^{2}$ ) due to hyperfiltration, which is common early in diabetes [8] and may mask the degree of kidney damage if eGFR is measured in isolation.

Although the importance of albuminuria screening in patients with T2D has been understood for many years, rates of testing remain suboptimal. The US Renal Data System has reported testing trends from 2016 in two populations of patients with T2D and without CKD: a Medicare $5 \%$ sample aged $\geq 65$ years and an Optum Clinformatics sample aged 22-64 years [1]. During that year, less than half of these patients in both the Medicare (42\%) and Optum Clinformatics (49\%) populations had undergone any urine albumin testing. Furthermore, different methods of assessing albuminuria were used, such as measurement of urinary protein, which has lower sensitivity for predicting kidney events compared with the UACR [18].

\section{MANAGEMENT OF CKD IN PATIENTS WITH T2D}

\section{Glycemic Control}

Intensive glycemic control in patients with T2D results in significant reductions in the development of microvascular complications, with the 
Table 2 ADA-recommended pharmacologic interventions and treatment goals for the management of CKD in T2D, together with relevant renal and cardiovascular outcomes findings from clinical studies

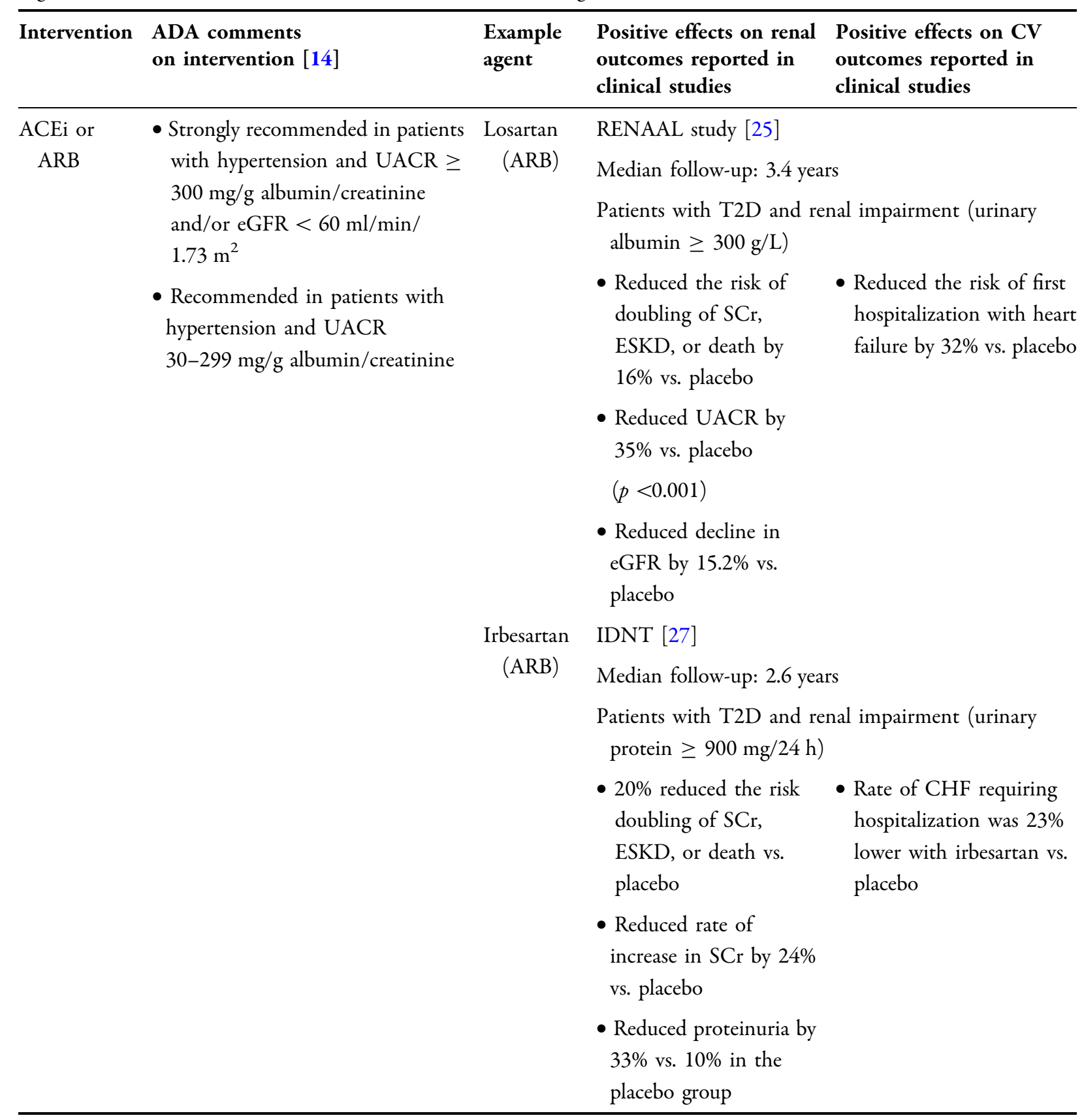


Table 2 continued

\begin{tabular}{|c|c|c|c|c|}
\hline Intervention & $\begin{array}{l}\text { ADA comments on } \\
\text { intervention [14] }\end{array}$ & $\begin{array}{l}\text { Example } \\
\text { agent }\end{array}$ & $\begin{array}{l}\text { Positive effects on renal } \\
\text { outcomes reported in clinical } \\
\text { studies }\end{array}$ & $\begin{array}{l}\text { Positive effects on } \\
\mathrm{CV} \text { outcomes } \\
\text { reported in clinical } \\
\text { studies }\end{array}$ \\
\hline SGLT-2i & $\begin{array}{l}\text { - Consider in patients with an } \\
\text { eGFR } \geq 30 \mathrm{~mL} / \mathrm{min} / \\
1.73 \mathrm{~m}^{2} \text { and } \\
\mathrm{UACR}>30 \mathrm{mg} / \mathrm{g} \text { albumin/ } \\
\text { creatinine, particularly in } \\
\text { those with } \\
\mathrm{UACR}>300 \mathrm{mg} / \mathrm{g} \\
\text { albumin/creatinine, to reduce } \\
\text { risk of CKD progression, } \\
\mathrm{CVD} \text {, or both }\end{array}$ & Canagliflozin & $\begin{array}{l}\text { CREDENCE trial [34] ( }+\mathrm{ACl} \\
\text { Median follow-up: } 2.6 \text { years } \\
\text { Patients with T2D and renal im } \\
\text { (eGFR } 30-90 \mathrm{~mL} / \mathrm{min} / 1.73 \mathrm{~m} \\
\text { albumin:creatinine }>300-500 \\
\text { - Reduced the relative risk of } \\
\text { ESKD, doubling of SCr, or } \\
\text { death from renal or CV } \\
\text { disease vs. placebo } \\
\text { - Geometric mean UACR was } \\
\text { 31\% lower for patients } \\
\text { receiving canagliflozin vs. } \\
\text { placebo during follow-up } \\
\text { - Decline in eGFR was slower } \\
\text { for patients receiving } \\
\text { canagliflozin vs. placebo after } \\
\text { the first } 3 \text { weeks } \\
\text { CANVAS program [ } 46] \\
\text { Median follow-up: } 2.2 \text { years } \\
\text { Patients with T2D and high CV } \\
\text { min/1.73 }{ }^{2} \text { ) } \\
\text { - Reduced the relative risk of } \\
\text { sustained } 40 \% \text { reduction in } \\
\text { eGFR, need for renal } \\
\text { replacement therapy, or death } \\
\text { from renal causes by } 40 \% \text { vs. } \\
\text { placebo (not significant) } \\
\text { - Reduced the relative risk of } \\
\text { progression of albuminuria by } \\
27 \% \text { vs. placebo (not } \\
\text { significant) }\end{array}$ & $\begin{array}{l}\text { risk (eGFR > } 30 \mathrm{~mL} \text { / } \\
\text { - Reduced the relative } \\
\text { risk of CV death, } \\
\text { MI, or stroke by } \\
14 \% \text { vs. placebo } \\
\text { - Reduced the relative } \\
\text { risk of } \\
\text { hospitalization for } \\
\text { heart failure by } 33 \% \\
\text { vs. placebo }\end{array}$ \\
\hline
\end{tabular}


Table 2 continued

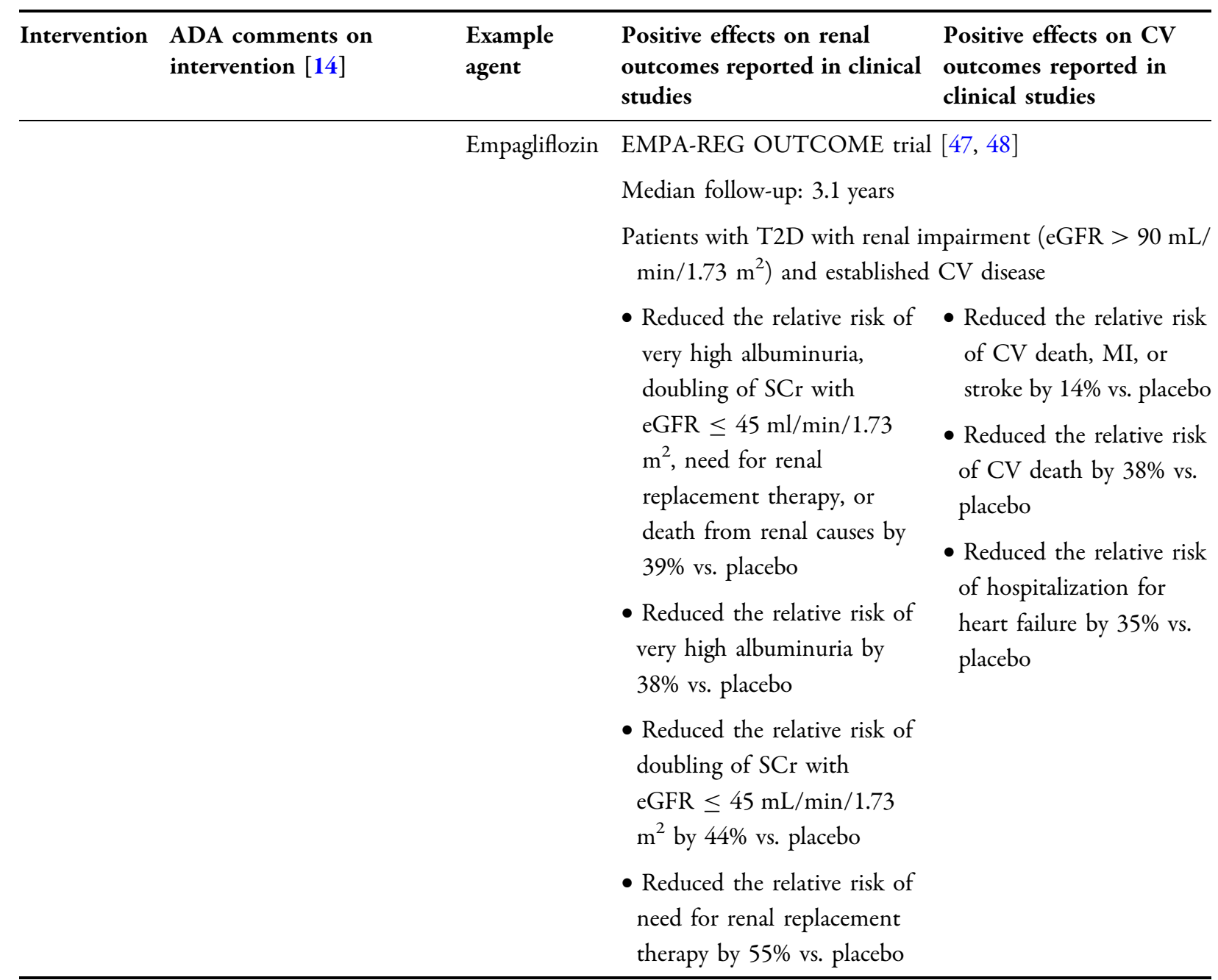


Table 2 continued

\begin{tabular}{|c|c|c|c|c|}
\hline Intervention & $\begin{array}{l}\text { ADA comments } \\
\text { on intervention [14] }\end{array}$ & $\begin{array}{l}\text { Example } \\
\text { agent }\end{array}$ & $\begin{array}{l}\text { Positive effects on renal } \\
\text { outcomes reported in clinical } \\
\text { studies }\end{array}$ & $\begin{array}{l}\text { Positive effects on CV } \\
\text { outcomes reported in } \\
\text { clinical studies }\end{array}$ \\
\hline & & \multirow[t]{13}{*}{ Dapagliflozin } & DECLARE-TIMI 58 trial [49] & \\
\hline & & & Median follow-up: 4.2 years & \\
\hline & & & $\begin{array}{l}\text { Patients with T2D and renal im } \\
\text { clearance }>60 \mathrm{~mL} / \mathrm{min} \text { ) }\end{array}$ & npairment (creatinine \\
\hline & & & $\begin{array}{l}\text { Reduced the relative risk } \\
\text { of } \geq 40 \% \text { reduction in } \\
\text { eGFR, ESKD, or death from } \\
\text { renal or CV causes by } 24 \% \\
\text { vs. placebo }\end{array}$ & $\begin{array}{l}\text { - Reduced the relative risk } \\
\text { of CV death or } \\
\text { hospitalization for heart } \\
\text { failure by } 17 \% \text { vs. placebo }\end{array}$ \\
\hline & & & $\begin{array}{l}\text { - Reduced the relative risk } \\
\text { of } \geq 40 \% \text { reduction in } \\
\text { eGFR, ESKD, or death from } \\
\text { renal causes by } 47 \% \text { vs. } \\
\text { placebo }\end{array}$ & $\begin{array}{l}\text { of hospitalization for } \\
\text { heart failure by } 27 \% \text { vs. } \\
\text { placebo }\end{array}$ \\
\hline & & & DAPA-CKD Trial & \\
\hline & & & Median follow-up: 2.4 years & \\
\hline & & & \multicolumn{2}{|c|}{$\begin{array}{l}\text { Patients with T2D and renal impairment (eGFR } \geq 25 \text { to } \\
75 \mathrm{~mL} / \mathrm{min} / 1.73 \mathrm{~m}^{2} \text { and albumin:creatinine } 200-5000\end{array}$} \\
\hline & & & $\begin{array}{l}\text { - Reduced the risk of sustained } \\
\text { decline in eGFR } \geq 50 \% \text {, } \\
\text { ESKD, or death from CV or } \\
\text { kidney causes by } 37 \% \text { vs. } \\
\text { placebo }\end{array}$ & $\begin{array}{l}\text { - Reduced the relative risk } \\
\text { of CV death or } \\
\text { hospitalization for heart } \\
\text { failure by } 28 \% \text { vs. placebo }\end{array}$ \\
\hline & & & - Reduced the risk of sustained & \\
\hline & & & decline in eGFR $\geq 50 \%$ & \\
\hline & & & ESKD, or death from kidney & \\
\hline & & & causes by $42 \%$ vs. placebo & \\
\hline
\end{tabular}


Table 2 continued

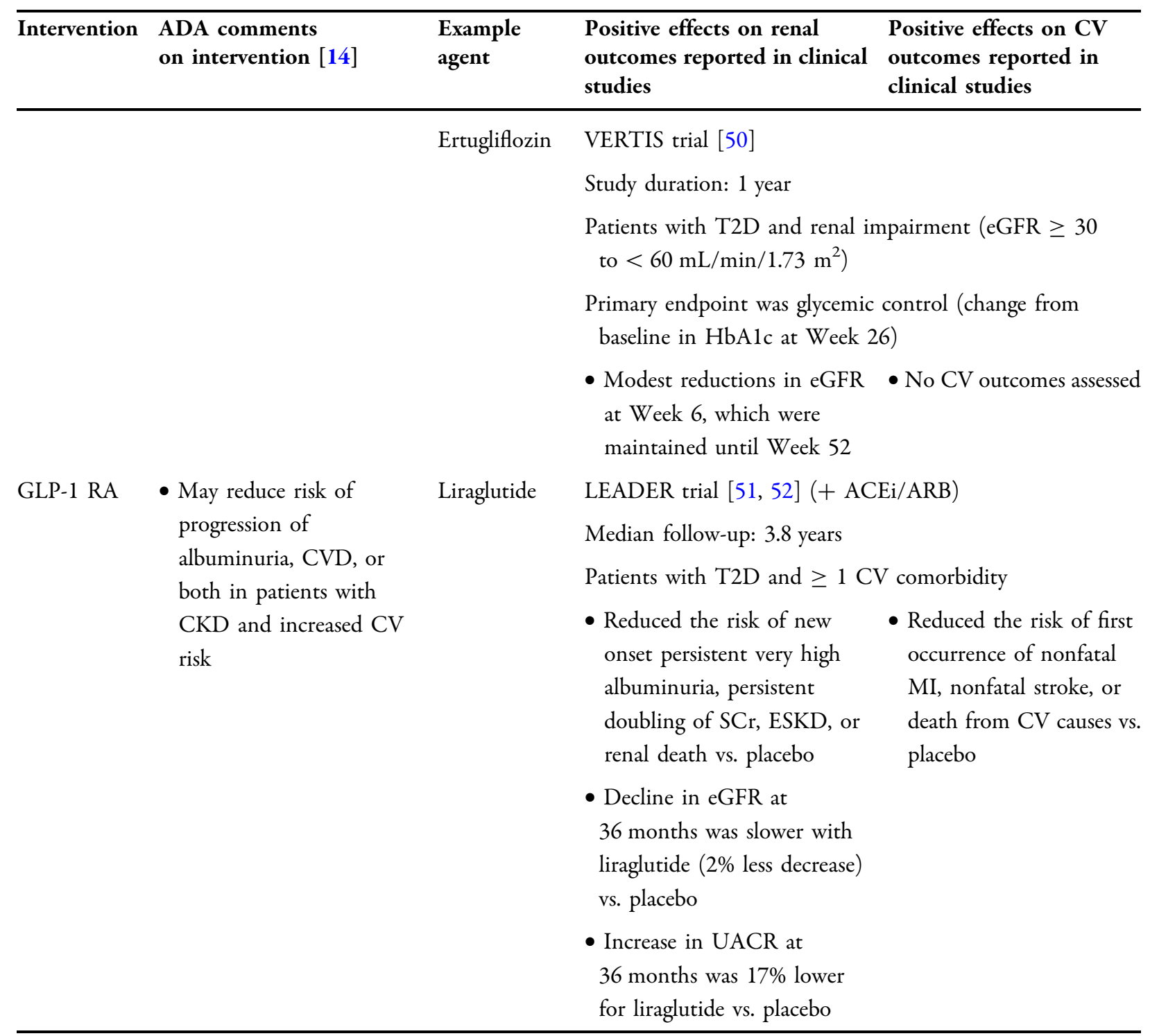


Table 2 continued

\begin{tabular}{|c|c|c|c|c|}
\hline Intervention & $\begin{array}{l}\text { ADA } \\
\text { comments } \\
\text { on } \\
\text { intervention } \\
{[14]}\end{array}$ & $\begin{array}{l}\text { Example } \\
\text { agent }\end{array}$ & $\begin{array}{l}\text { Positive effects on renal outcomes } \\
\text { reported in clinical studies }\end{array}$ & $\begin{array}{l}\text { Positive effects on CV outcomes } \\
\text { reported in clinical studies }\end{array}$ \\
\hline & & \multirow{4}{*}{$\begin{array}{l}\text { Semaglutide } \\
\text { (injectable) }\end{array}$} & \multicolumn{2}{|l|}{ SUSTAIN-6 trial [53] } \\
\hline & & & \multicolumn{2}{|l|}{ Median follow-up: 2.1 years } \\
\hline & & & \multicolumn{2}{|c|}{ Patients with T2D and established CVD or CKD stage $>3$} \\
\hline & & & $\begin{array}{l}\text { Reduced the relative risk of very } \\
\text { high albuminuria, doubling of } \mathrm{SCr} \\
\text { with } \mathrm{eGFR}<45 \mathrm{~mL} / \mathrm{min} / \\
1.73 \mathrm{~m}^{2} \text {, or need for renal } \\
\text { replacement therapy by } 36 \% \text { vs. } \\
\text { placebo }\end{array}$ & $\begin{array}{l}\text { - Reduced the relative risk of CV } \\
\text { death, MI, or stroke by } 26 \% \text { vs. } \\
\text { placebo } \\
\text { - Reduced the relative risk of CV } \\
\text { death, MI, stroke, revascularization, } \\
\text { or hospitalization for heart failure } \\
\text { or unstable angina by } 26 \% \text { vs. } \\
\text { placebo }\end{array}$ \\
\hline & & Semaglutide & \multicolumn{2}{|l|}{ PIONEER-6 trial [54] } \\
\hline & & (oral) & \multicolumn{2}{|l|}{ Median follow-up: 1.3 years } \\
\hline & & & \multicolumn{2}{|c|}{ Patients with T2D and established CV disease or CKD } \\
\hline & & & - Not reported & $\begin{array}{l}\text { - Did not reduce the relative risk of } \\
\text { CV death, MI, or stroke vs. } \\
\text { placebo } \\
\text { - Reduced the relative risk of CV } \\
\text { death by } 51 \% \text { vs. placebo }\end{array}$ \\
\hline & & Dulaglutide & \multicolumn{2}{|l|}{ REWIND trial $[55,56]$} \\
\hline & & & \multicolumn{2}{|l|}{ Median follow-up: 5.4 years } \\
\hline & & & \multicolumn{2}{|c|}{ Patients with $\mathrm{T} 2 \mathrm{D}$ and $\mathrm{CV}$ event or risk factors } \\
\hline & & & $\begin{array}{l}\text { - Reduced relative risk of new-onset } \\
\text { UACR }>33.9 \mathrm{mg} / \mathrm{mmol} \text {, } \\
\text { sustained } \geq 30 \% \text { reduction in } \\
\text { eGFR, or need for renal } \\
\text { replacement therapy by } 15 \% \text { vs. } \\
\text { placebo } \\
\text { - Reduced relative risk of new-onset } \\
\text { UACR }>33.9 \mathrm{mg} / \mathrm{mmol} \text { by } 23 \% \\
\text { vs. placebo }\end{array}$ & $\begin{array}{l}\text { - Reduced the relative risk of CV } \\
\text { death, MI, or stroke by } 12 \% \text { vs. } \\
\text { placebo }\end{array}$ \\
\hline
\end{tabular}


Table 2 continued

\begin{tabular}{lllll}
\hline Intervention & $\begin{array}{l}\text { ADA } \\
\text { comments } \\
\text { on } \\
\text { intervention }\end{array}$ & $\begin{array}{l}\text { Example } \\
\text { agent }\end{array}$ & $\begin{array}{l}\text { Positive effects on renal outcomes } \\
\text { reported in clinical studies }\end{array}$ & $\begin{array}{l}\text { Positive effects on CV outcomes } \\
\text { reported in clinical studies }\end{array}$ \\
& & & \\
{$[14]$} & & & \\
\hline
\end{tabular}

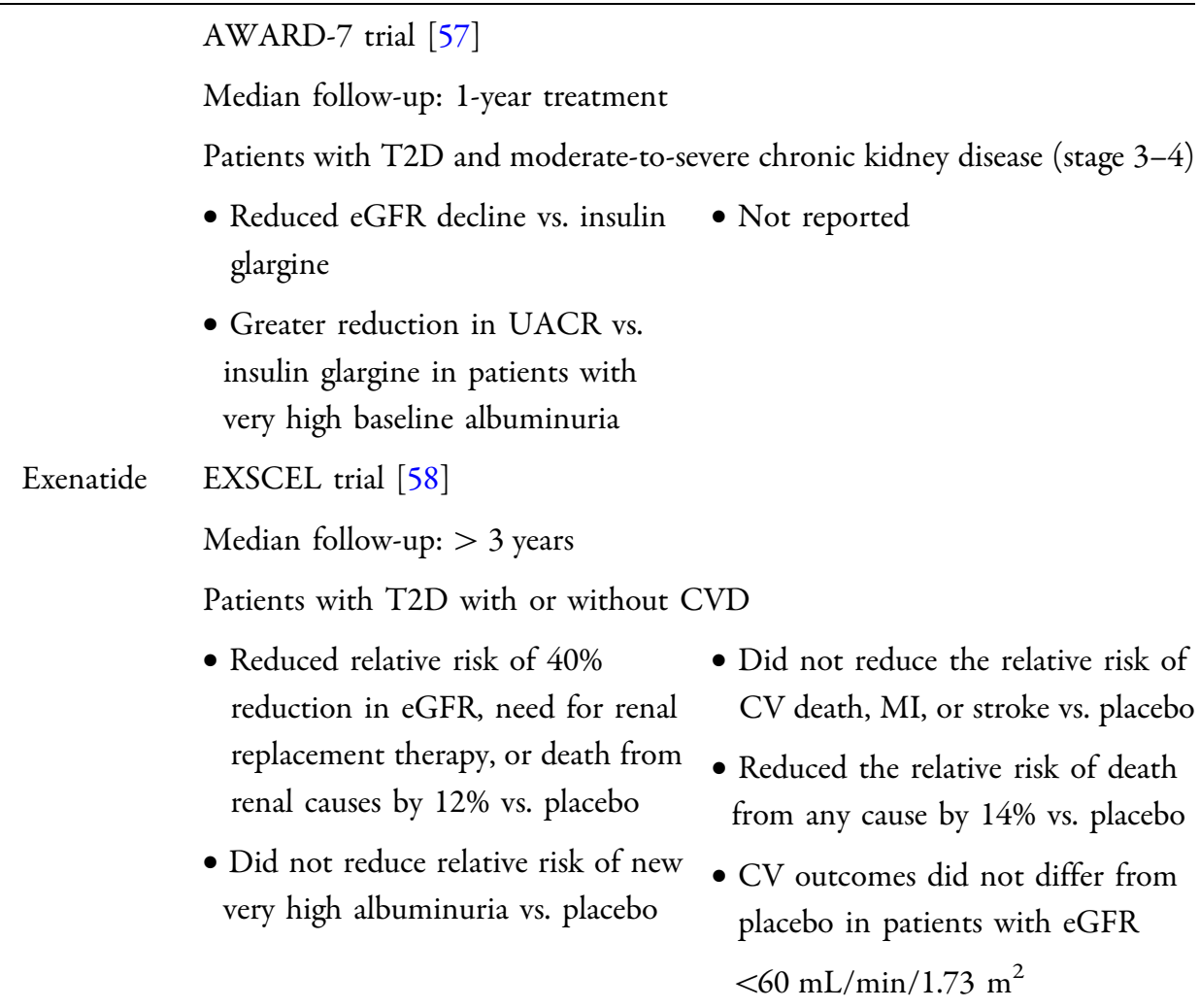

Lixisenatide ELIXA trial (patients with T2D and ACS) $[59,60]$

Median follow-up: 2.1 years

Patients with T2D with recent acute coronary event

- Greater reduction in UACR vs. placebo (34\% vs. $24 \%)$

- Greater reduction in UACR vs. placebo in patients with very high albuminuria at baseline ( $42 \%$ vs.
- Did not reduce the relative risk of CV death, MI, or stroke vs. placebo $2 \%)$

$A C E i$ angiotensin-converting enzyme inhibitor, $A C S$ acute coronary syndrome, $A R B$ angiotensin II receptor blocker, $C H F$ congestive heart failure, CREDENCE Canagliflozin and Renal Events in Diabetes with Established Nephropathy Clinical Evaluation; CV, cardiovascular; eGFR estimated glomerular filtration rate, ESKD end-stage kidney disease, GLP-1 RA glucagon-like peptide-1 receptor agonist, IDNT Irbesartan Diabetic Nephropathy Trial, LEADER liraglutide effect and action in diabetes: evaluation of cardiovascular outcome results, $M I$ myocardial infarction, RENAAL Reduction of Endpoints in NIDDM with the Angiotensin II Antagonist Losartan, $S C r$ serum creatinine concentration, SGLT-2i sodium-glucose cotransporter-2 inhibitor, $U A C R$ urine albumin-to-creatinine ratio 
evidence of prevention of incident CKD being stronger than that for decreasing progression of established CKD $[19,20]$. Therefore, the ADA guidelines provide treatment goals for glucose control (target levels of glycated hemoglobin [A1C], described in Table 1), and recommend that $\mathrm{A} 1 \mathrm{C}$ is assessed at least twice per year in patients meeting these goals, and quarterly in patients who have switched therapy or who are not meeting treatment goals [14]. This approach is endorsed in the Kidney Disease Improving Global Outcomes (KDIGO ${ }^{\circledR}$ ) 2020 Clinical Practice Guidelines [17]. It is important to note that in patients with advanced CKD, A1C levels may be falsely low, and therefore patients with T2D and CKD should be encouraged to self-monitor their blood glucose levels more frequently [21]. This is due to patients commonly having anemia of chronic disease, and the decreased survival time of erythrocytes in these patients leads to falsely low A1C results [22]. The incidence of adverse effects associated with intensive glycemic control is increased in patients with concomitant CKD, so careful individualization of glycemic goals is recommended (Table 1) [14].

\section{Dietary Intervention}

Dietary interventions can help to improve blood pressure (BP) and glucose control, as well as slow the progression of CKD [14]. Recommended nutritional interventions include protein intake of approximately $0.8 \mathrm{~g} / \mathrm{kg} /$ day and sodium intake $<2300 \mathrm{mg} /$ day (ADA) or $<2000 \mathrm{mg} /$ day (KDIGO) [14, 17] Dietary protein intake less than the recommended daily allowance of $0.8 \mathrm{~g} / \mathrm{kg} /$ day does not improve outcomes. For patients on dialysis, higher levels of dietary protein intake should be considered, as malnutrition is a problem in some dialysis patients $[14,17]$. It is helpful to have the input of a registered dietician or a certified diabetes educator to help operationalize these goals for patients.

\section{BP Control}

Patients with CKD are at increased risk of developing both kidney failure and CVD [1]. The prevalence of CVD in US persons aged $\geq$ 66 years is twofold higher in those with CKD $(69.6 \%)$ than in those without (34.7\%) [10]. CVD is a leading cause of death in patients with CKD regardless of disease stage, accounting for over a quarter of deaths in patients with early (stage 1 or 2) CKD and more than half of deaths in patients with ESKD [23].

Patients with T2D and hypertension should receive appropriate treatment to reduce their risk of atherosclerotic CVD events, heart failure, and microvascular complications [14]. BP levels $<140 / 90 \mathrm{mmHg}$ are recommended by the ADA to reduce CVD mortality and slow CKD progression among all people with diabetes. Patients with CKD are at increased risk of CKD progression (particularly those with albuminuria) and CVD and, therefore, may be suitable in some cases for lower BP targets [14]. The ADA states that lower BP targets $(<130 /$ $80 \mathrm{mmHg}$ ) should be considered for patients based on individual anticipated benefits and risks. It should be noted that there are varying recommendations for BP control between different governing bodies. The 2020 International Society of Hypertension Global Hypertension Practice Guidelines recommends that for patients with CKD, "Blood pressure should be lowered if $\geq 140 / 90 \mathrm{mmHg}$ and treated to a target $<130 / 80 \mathrm{mmHg} \quad(<140 / 80 \quad$ in elderly patients)" [24]. Patients with hypertension and albuminuria (UACR $\geq 30 \mathrm{mg} / \mathrm{g}$ albumin/creatinine) should initially receive treatment with the maximum tolerated dose of either an ACEi or an ARB, as agents targeting the renin-angiotensin system have demonstrated kidney protective effects in clinical trials (Table 2) $[14,17,25-27]$. If a patient cannot tolerate treatment with an ACEi, treatment should be switched to an ARB, or vice-versa [14]. ACEis and ARBs should not be used concomitantly due to an increased risk of adverse events, including hyperkalemia and acute kidney injury [14].

Despite the guideline recommendations advocating the use of ACEis/ARBs in patients 
with T2D and CKD, reported rates of the use of these agents remain low. Although specific data regarding the use of ACEis/ARBs in patients with T2D and CKD are lacking, rates of use in patients with CKD and hypertension are low (only $36 \%$ of patients received an ACEi/ARB between 2010 and 2014) and have decreased since 2006 [28]. There is evidence to suggest that patients with CKD who are comanaged by a PCP and a nephrologist have higher ACEi/ARB prescription rates [29] and that patients with more severe renal impairment are more likely to receive an ACEi/ARB when they have received care from both a PCP and a nephrologist compared with a PCP alone [30]. Notably, PCPs may have reservations about prescribing ACEis/ARBs given the potential risk for developing hyperkalemia. To mitigate the risk of hyperkalemia, the Kidney Disease Outcomes Quality Initiative (KDOQI) guidelines recommend starting ACEi/ ARBs at a lower dose and titrating upwards in patients with an eGFR $>45 \mathrm{~mL} / \mathrm{min} / 1.73 \mathrm{~m}^{2}$ [31]. Importantly, eGFR and serum potassium should be monitored within a few weeks of a patient starting an ACEi/ARB [31]. If hyperkalemia develops, consideration for a nephrology referral is appropriate. Additional strategies that can be considered include identification and restriction of dietary potassium, treatment of metabolic acidosis where required, initiation/ up titration of thiazide or loop diuretic(s) to increase potassium excretion, and treatment with a potassium-binding exchange resin [31].

\section{Choice of Glucose-Lowering Agent}

Sodium-glucose cotransporter-2 inhibitors (SGLT-2is) and glucagon-like peptide 1 receptor agonists (GLP-1 RAs) have demonstrated beneficial effects on kidney and cardiovascular outcomes. GLP-1 RAs have been shown to decrease the progression of microalbuminuria, while SGLT-2is have been shown to both decrease progression of microalbuminuria and slow the decline in eGFR $[32,33]$. Evidence supporting the kidney protective benefits of SGLT-2is comes from the Canagliflozin and Renal Events in Diabetes with Established Nephropathy Clinical Evaluation (CREDENCE) and
Dapagliflozin and Prevention of Adverse Outcomes in CKD (DAPA-CKD) studies [34, 35], which showed that canagliflozin and dapagliflozin on a background of ACEi/ARBs reduced the incidence of the composite primary (Table 2), as well as post hoc analyses of placebo-controlled cardiovascular outcomes trials of empagliflozin, dapagliflozin, and ertugliflozin (Table 2).

Both SGLT-2is and GLP-1 RAs have been shown to reduce major cardiac adverse events. The SGLT-2is dapagliflozin, canagliflozin, and empagliflozin reduce the risk of hospitalization for heart failure in patients with T2D and CKD, whereas ertugliflozin does not (Table 2) [33]. The GLP-1 RAs liraglutide, semaglutide (injection), and dulaglutide reduce the risk of cardiovascular death, myocardial infarction, and/ or stroke relative to placebo, whereas semaglutide (oral), exenatide, and lixisenatide do not (Table 2).

The ADA recommends that independent of baseline $\mathrm{A} 1 \mathrm{C}$ or individualized $\mathrm{A} 1 \mathrm{C}$ target, if a patient has heart failure or CKD, then an SGLT$2 \mathrm{i}$ with evidence of reducing heart failure and/ or CKD progression should be a part of a patient's glucose-lowering regimen as long as the eGFR is adequate for the use of an SGLT-2i. If an SGLT-2i is not tolerated or if the eGFR is less than can be used with an SGLT-2i, then a GLP-1 RA should be used [14]. SGLT-2is and GLP-1 RAs can also be used for the treatment of patients who are unable to use or tolerate metformin. In the KDIGO guidelines, an SGLT2i is recommended for the treatment of patients with T2D, CKD, and an eGFR $\geq 30 \mathrm{~mL} / \mathrm{min} /$ $1.73 \mathrm{~m}^{2}$, and if metformin and SGLT2is are not effective or unusable, a long-acting GP-1 RA is recommended [17].

\section{Reducing Cardiorenal Outcomes: Agents in Development}

Tight glycemic and BP control, along with the use of recommended agents, can slow CKD onset and progression. However, progression of CKD still does occur for many patients. Agents that may provide additive beneficial effects on slowing progression of CKD and decreasing the 
incidence of CVD are currently being evaluated. These include the selective endothelin-A receptor antagonist atrasentan [36] and the mineralocorticoid receptor antagonist (MRA) finerenone [37, 38]

Endothelin receptor antagonists reduce BP and proteinuria in patients with T2D and CKD but have been associated with fluid retention, which can be life-threatening [39]. The recent Study Of diabetic Nephropathy with AtRasentan (SONAR) study was carried out to evaluate the effects of atrasentan in patients with T2D and CKD [36]. Enrolled patients who responded to 6 weeks of atrasentan $0.75 \mathrm{mg}$ daily with $\geq 30 \%$ decrease in UACR without fluid retention were randomized to continued atrasentan or placebo. After a median follow-up of 2.2 years, the risk of increased kidney disease (composite kidney endpoint of ESKD or doubling of serum creatinine for $\geq 30$ days) was reduced by $35 \%$. The risk for cardiorenal events (composite endpoint comprising: doubling serum creatinine, ESKD, cardiovascular death, non-fatal myocardial infarction, or non-fatal stroke) was also reduced, although atrasentan had no effect on a composite CVD measure (cardiovascular death, non-fatal myocardial infarction, or non-fatal stroke) [36]. However, the rates of anemia and hypervolemia were higher in the atrasentan group than in the placebo group. The rate of hospitalization for heart failure was numerically, but not statistically significantly, higher in the atrasentan group [36].

Non-steroidal MRAs have also been shown to reduce albuminuria in clinical trials in patients with CKD in T2D. Following encouraging results from a phase II trial, ARTS-DN, finerenone, a novel non-steroidal MRA is now being evaluated for the reduction of kidney and cardiovascular outcomes in patients with T2D and CKD in a large clinical trial program $[37,38]$. The results of the FIDELIO-DKD study $(n=5734)$ have been recently reported, while the FIGARO-DKD study $(n=7437)$ is ongoing and study completion is expected in July 2021 [38].

FIDELIO-DKD recruited patients aged $\geq$ 18 years with T2D and CKD with eGFR ( $\geq 25$ to $<60 \mathrm{~mL} / \mathrm{min} / 1.73 \mathrm{~m}^{2}$ ), UACR (30 to $<300 \mathrm{mg}$ / g), and a history of diabetic retinopathy; or eGFR ( $\geq 25$ to $<75 \mathrm{~mL} / \mathrm{min} / 1.73 \mathrm{~m}^{2}$ ), UACR ( $\geq$ $300 \mathrm{mg} / \mathrm{g}$ ), and a serum potassium $\leq 4.8 \mathrm{mmol} /$ L. Patents with heart failure with reduced ejection fraction were excluded from study, ACEis/ ARBs were maximized in a 16-week run-in, and doses were stable for $\geq 4$ weeks prior to randomization.

The primary composite endpoint was time to first occurrence of kidney failure (ESKD or eGFR $<15 \mathrm{~mL} / \mathrm{min} / 1.73 \mathrm{~m}^{2}$ ), a sustained decrease of eGFR $\geq 40 \%$ from baseline over at least 4 weeks, or renal death [37]. The incidence of the primary composite outcome was significantly lower in the finerenone group than in the placebo group (504 patients [17.8\%] vs. 600 patients [21.1\%]; hazard ratio (HR) $0.82 ; 95 \%$ confidence interval (CI) $0.73-0.93 ; p=0.001$ ) with a number needed to treat (NNT) of 29 at 3 years [40]. Furthermore, the incidence of the secondary outcome (death from cardiovascular causes, non-fatal myocardial infarction, nonfatal stroke, or hospitalization for heart failure) was also lower with finerenone treatment (367 patients [13.0\%] vs. 420 patients [14.8\%]; HR 0.86 ; 95\% CI $0.75-0.99 ; p=0.03$ ) with an NNT of 42 [40]. The reduction in UACR from baseline to month 4 was greater with finerenone compared with placebo (31\% reduction), and the incidence of the secondary composite kidney outcome (kidney failure, sustained decrease of $\geq$ $57 \%$ in the eGFR from baseline [consistent with a doubling of serum creatinine], or death from kidney causes) occurred in fewer patients in the finerenone group (252 patients [8.9\%] vs. 326 patients [11.5\%]; HR 0.76; 95\% CI 0.65-0.90) [40]. Finerenone was generally well tolerated with a similar incidence of adverse events observed between the finerenone and placebo groups. Although finerenone was associated with a higher overall risk of hyperkalemia compared with placebo, discontinuation due to hyperkalemia was low in patients receiving finerenone compared with those receiving placebo $(2.3$ vs. $0.9 \%)$. Notably, these rates of discontinuations were lower than in trials of dual RAS blockade (combination of direct renin inhibitor + ACEi or ARB 4.8\%; combination therapy with ACEi + ARB 9.2\%) [41, 42]. 
Studies of the steroidal MRAs spironolactone or eplerenone in combination with an ACEi/ ARB have demonstrated reductions in BP and in albuminuria in patients with diabetes and kidney disease [43]. However, this combination is associated with an increased incidence of hyperkalemia, resulting in high rates of treatment discontinuation $[43,44]$.

\section{Nephrologist Referral}

Appropriate referral of patients to a nephrologist for specialist assessment is encouraged as it is associated with improved quality of care, delayed dialysis, and reduced costs [14, 45]. Comanagement of patients with T2D and CKD by their PCP and a nephrologist have also been associated with significantly increased rates of eGFR testing and prescription of an ACEi/ARB [29]. Guidance for referral (based on GFR and albuminuria) is shown in Fig. 1. Referrals should be considered if the cause of CKD is unclear, or if there are issues with disease management, such as for patients with anemia, secondary hyperparathyroidism, metabolic bone disease, resistant hypertension, or electrolyte disturbances. Patients should also be referred if they have stage 4 CKD $\left(e G F R<30 \mathrm{~mL} / \mathrm{min} / 1.73 \mathrm{~m}^{2}\right)$ to plan for kidney replacement therapy [14].

\section{CONCLUSIONS}

Despite guideline recommendations to screen for CKD in patients with T2D, many patients remain underdiagnosed and undertreated. Evidence from recently completed clinical trials indicate that progressive kidney disease and cardiovascular outcomes can be slowed or prevented by treatment including ACEis/ARBs, SGLT2-is, GLP-1 RAs, and non-steroidal MRAs. We now have the opportunity to target multiple pathways in the treatment of CKD in patients with T2D, which lends itself to optimizing therapy based on the individual patients' clinical needs. New treatments are currently under investigation and results from large cardiorenal studies, specifically in patients with CKD and T2D, are anticipated in 2021.

\section{ACKNOWLEDGEMENTS}

Funding. No funding or sponsorship was received for this study or publication of this article.

Authorship. All named authors meet the International Committee of Medical Journal Editors (ICMJE) criteria for authorship for this article, take responsibility for the integrity of the work as a whole, and have given their approval for this version to be published. Both authors participated in the drafting, critical revision, and approval of the final version of the manuscript.

Medical Writing, Editorial, and Other Assistance. Medical writing assistance was provided by Tania Dickson, PhD, CMPP, of Envision Pharma Group, and was funded by Bayer Corporation. ProScribe's services complied with international guidelines for Good Publication Practice (GPP3).

Disclosures. Dr. Alyssa Style has no relevant conflicts to disclose. Dr. Neil Skolnik reports "personal fees" and "other" for activities outside the submitted work from AstraZeneca, Boehringer Ingelheim, GSK, Sanofi, and Sanofi Pasteur. Additionally, Dr. Skolnik reports "nonfinancial support" for activities outside the submitted work from Eli Lilly and Company, Intarcia Therapeutics, Merck and Company, Mylan, and Teva Pharmaceuticals.

Compliance with Ethics Guidelines. This article is based on previously conducted studies and does not contain any studies with human participants or animals performed by any of the authors.

Data Availability. Data sharing is not applicable to this article as no datasets were generated or analyzed during the current study.

Open Access. This article is licensed under a Creative Commons Attribution-NonCommercial 4.0 International License, which permits any non-commercial use, sharing, 
adaptation, distribution and reproduction in any medium or format, as long as you give appropriate credit to the original author(s) and the source, provide a link to the Creative Commons licence, and indicate if changes were made. The images or other third party material in this article are included in the article's Creative Commons licence, unless indicated otherwise in a credit line to the material. If material is not included in the article's Creative Commons licence and your intended use is not permitted by statutory regulation or exceeds the permitted use, you will need to obtain permission directly from the copyright holder. To view a copy of this licence, visit http:// creativecommons.org/licenses/by-nc/4.0/.

\section{REFERENCES}

1. United States Renal Data System. 2018 USRDS annual data report. Executive summary. Bethesda: National Institute of Diabetes and Digestive and Kidney Diseases, National Institutes of Health; 2018. https://www.usrds.org/annual-data-report/ previous-adrs/. Accessed 18 Jan 2021.

2. United States Renal Data System. 2019 USRDS annual data report. Executive summary. Bethesda: National Institute of Diabetes and Digestive and Kidney Diseases, National Institutes of Health; 2019. https://www.usrds.org/annual-data-report/ previous-adrs/. Accessed 18th January 2021

3. Umanath $\mathrm{K}$, Lewis JB. Update on diabetic nephropathy: core curriculum 2018. Am J Kidney Dis. 2018;71(6):884-95.

4. Afkarian M, Sachs MC, Kestenbaum B, et al. Kidney disease and increased mortality risk in type 2 diabetes. J Am Soc Nephrol. 2013;24(2):302-8.

5. Cea Soriano L, Johansson S, Stefansson B, Rodriguez LA. Cardiovascular events and all-cause mortality in a cohort of 57,946 patients with type 2 diabetes: associations with renal function and cardiovascular risk factors. Cardiovasc Diabetol. 2015;14:38.

6. International Diabetes Federation. IDF diabetes atlas. 9th ed. Brussels, Belgium: International Diabetes Federation; 2019.

7. Centers for Disease Control and Prevention. National diabetes statistics report, 2020. Atlanta: Centers for Disease Control and Prevention, U.S. Dept of Health and Human Services; 2020.
8. Alicic RZ, Rooney MT, Tuttle KR. Diabetic kidney disease: challenges, progress, and possibilities. Clin J Am Soc Nephrol. 2017;12(12):2032-45.

9. Zimbudzi E, Lo C, Ranasinha S, Gallagher M, Fulcher G, Kerr PG, et al. Predictors of health-related quality of life in patients with co-morbid diabetes and chronic kidney disease. PLoS ONE. 2016;11(12):e0168491.

10. National Institute of Diabetes and Digestive and Kidney Diseases. Kidney disease statistics for the United States 2020. https://www.niddk.nih.gov/ health-information/health-statistics/kidneydisease. Accessed Jan 2021.

11. United States Renal Data System. 2017 USRDS annual data report. Epidemiology of kidney disease in the United States. Bethesda: US Department of Health and Human Services, National Institutes of Health, National Institute of Diabetes and Digestive and Kidney Diseases; 2016. https://www.usrds.org/ adr.aspx. Accessed Jan 2021.

12. Burrows NR, Hora I, Geiss LS, Gregg EW, Albright A. Incidence of end-stage renal disease attributed to diabetes among persons with diagnosed diabetesUnited States and Puerto Rico, 2000-2014. MMWR Morb Mortal Wkly Rep. 2017;66(43):1165-70.

13. Levey AS, Becker C, Inker LA. Glomerular filtration rate and albuminuria for detection and staging of acute and chronic kidney disease in adults: a systematic review. JAMA. 2015;313(8):837-46.

14. American Diabetes Association. Standards of medical care in diabetes. Diabetes Care. 2020;43(Suppl 1):S1-204.

15. Qaseem A, Hopkins RH Jr, Sweet DE, Starkey M, Shekelle P, Clinical Guidelines Committee of the American College of Physicians. Screening, monitoring, and treatment of stage 1 to 3 chronic kidney disease: A clinical practice guideline from the American College of Physicians. Ann Intern Med. 2013;159(12):835-47.

16. Gaitonde DY, Cook DL, Rivera IM. Chronic kidney disease: detection and evaluation. Am Fam Physician. 2017;96(12):776-83.

17. Kidney Disease: Improving Global Outcomes (KDIGO) Diabetes Work Group. KDIGO 2020 clinical practice guideline for diabetes management in chronic kidney disease. Kidney Int. 2020;98(4S): S1-S115.

18. Lambers Heerspink HJ, Gansevoort RT, et al. Comparison of different measures of urinary protein excretion for prediction of renal events. J Am Soc Nephrol. 2010;21(8):1355-60. 
19. Holman RR, Paul SK, Bethel MA, Matthews DR, Neil HA. 10-year follow-up of intensive glucose control in type 2 diabetes. N Engl J Med. 2008;359(15): 1577-89.

20. Ohkubo $\mathrm{Y}$, Kishikawa $\mathrm{H}$, Araki E, et al. Intensive insulin therapy prevents the progression of diabetic microvascular complications in Japanese patients with non-insulin-dependent diabetes mellitus: a randomized prospective 6-year study. Diabetes Res Clin Pract. 1995;28(2):103-17.

21. Bloomgarden Z, Handelsman Y. How does CKD affect HbA1c? J Diabetes. 2018;10(4):270.

22. Radin MS. Pitfalls in hemoglobin A1c measurement: when results may be misleading. J Gen Intern Med. 2014;29(2):388-94.

23. Gansevoort RT, Correa-Rotter R, Hemmelgarn BR, et al. Chronic kidney disease and cardiovascular risk: epidemiology, mechanisms, and prevention. Lancet. 2013;382(9889):339-52.

24. Unger T, Borghi C, Charchar F, et al. 2020 International society of hypertension global hypertension practice guidelines. Hypertension. 2020;75(6): 1334-57.

25. Brenner BM, Cooper ME, de Zeeuw D, et al. Effects of losartan on renal and cardiovascular outcomes in patients with type 2 diabetes and nephropathy. N Engl J Med. 2001;345(12):861-9.

26. Emdin CA, Rahimi K, Neal B, Callender T, Perkovic $\mathrm{V}$, Patel A. Blood pressure lowering in type 2 diabetes: a systematic review and meta-analysis. JAMA. 2015;313(6):603-15.

27. Lewis EJ, Hunsicker LG, Clarke WR, et al. Renoprotective effect of the angiotensin-receptor antagonist irbesartan in patients with nephropathy due to type 2 diabetes. N Engl J Med. 2001;345(12): 851-60.

28. Tummalapalli SL, Powe NR, Keyhani S. Trends in quality of care for patients with CKD in the United States. Clin J Am Soc Nephrol. 2019;14(8):1142-50.

29. Samal L, Wright A, Waikar SS, Linder JA. Nephrology co-management versus primary care solo management for early chronic kidney disease: a retrospective cross-sectional analysis. BMC Nephrol. 2015;16:162.

30. Ricardo AC, Roy JA, Tao K, et al. Influence of nephrologist care on management and outcomes in adults with chronic kidney disease. J Gen Intern Med. 2016;31(1):22-9.

31. Vassalotti JA, Centor R, Turner BJ, et al. Practical approach to detection and management of chronic kidney disease for the primary care clinician. Am J Med. 2016;129(2):153-162.e7.

32. Toyama T, Neuen BL, Jun M, et al. Effect of SGLT2 inhibitors on cardiovascular, renal and safety outcomes in patients with type 2 diabetes mellitus and chronic kidney disease: A systematic review and meta-analysis. Diabetes Obes Metab. 2019;21(5): 1237-50.

33. Zelniker TA, Wiviott SD, Raz I, et al. Comparison of the effects of glucagon-like peptide receptor agonists and sodium-glucose cotransporter 2 inhibitors for prevention of major adverse cardiovascular and renal outcomes in type 2 diabetes mellitus. Circulation. 2019;139(17):2022-31.

34. Perkovic V, Jardine MJ, Neal B, et al. Canagliflozin and renal outcomes in type 2 diabetes and nephropathy. N Engl J Med. 2019;380(24): 2295-306.

35. Heerspink HJL, Stefansson BV, Correa-Rotter R, et al. Dapagliflozin in patients with chronic kidney disease. N Engl J Med. 2020;383(15):1436-46.

36. Heerspink HJL, Parving $\mathrm{HH}$, Andress DL, et al. Atrasentan and renal events in patients with type 2 diabetes and chronic kidney disease (SONAR): a double-blind, randomised, placebo-controlled trial. Lancet. 2019;393(10184):1937-47.

37. Bakris GL, Agarwal R, Anker SD, et al. Design and baseline characteristics of the Finerenone in Reducing Kidney Failure and Disease Progression in Diabetic Kidney Disease trial. Am J Nephrol. 2019;50(5):333-44.

38. Ruilope LM, Agarwal R, Anker SD, et al. Design and baseline characteristics of the finerenone in reducing cardiovascular mortality and morbidity in diabetic kidney disease trial. Am J Nephrol. 2019;50(5): 345-56.

39. Mann JF, Green D, Jamerson K, et al. Avosentan for overt diabetic nephropathy. J Am Soc Nephrol. 2010;21(3):527-35.

40. Bakris GL, Agarwal R, Anker SD, et al. Effect of finerenone on chronic kidney disease outcomes in type 2 diabetes. N Engl J Med. 2020;383(23): 2219-29.

41. Parving HH, Brenner BM, McMurray JJ, et al. Cardiorenal end points in a trial of aliskiren for type 2 diabetes. N Engl J Med. 2012;367(23):2204-13.

42. Imai E, Chan JC, Ito S, et al. Effects of olmesartan on renal and cardiovascular outcomes in type 2 diabetes with overt nephropathy: a multicentre, randomised, placebo-controlled study. Diabetologia. 2011;54(12):2978-86. 
43. Mavrakanas TA, Gariani K, Martin PY. Mineralocorticoid receptor blockade in addition to angiotensin converting enzyme inhibitor or angiotensin II receptor blocker treatment: an emerging paradigm in diabetic nephropathy: a systematic review. Eur J Intern Med. 2014;25(2):173-6.

44. Trevisan M, de Deco P, Xu H, et al. Incidence, predictors and clinical management of hyperkalaemia in new users of mineralocorticoid receptor antagonists. Eur J Heart Fail. 2018;20(8):1217-26.

45. Smart NA, Dieberg G, Ladhani M, Titus T. Early referral to specialist nephrology services for preventing the progression to end-stage kidney disease. Cochrane Database Syst Rev. 2014(6): CD007333.

46. Neal B, Perkovic V, Mahaffey KW, de Zeeuw D, Fulcher G, Erondu N, et al. Canagliflozin andcardiovascular and renal events in type 2 diabetes. N Engl J Med. 2017;377(7):644-57.

47. Zinman B, Wanner C, Lachin JM, et al. Empagliflozin, cardiovascular outcomes, and mortality in type 2 diabetes. N Engl J Med. 2015;373(22): 2117-28.

48. Wanner C, Inzucchi SE, Lachin JM, et al. Empagliflozin and progression of kidney disease in type 2 diabetes. N Engl J Med. 2016;375(4):323-34.

49. Wiviott SD, Raz I, Bonaca MP, et al. Dapagliflozin and cardiovascular outcomes in type 2 diabetes. N Engl J Med. 2018;380(4):347-57.

50. Grunberger G, Camp S, Johnson J, et al. Ertugliflozin in patients with stage 3 chronic kidney disease and Type 2 diabetes mellitus: The VERTIS renal randomized Study. Diabetes Ther. 2018;9(1):49-66.

51. Mann JFE, Orsted DD, Brown-Frandsen K, et al. Liraglutide and renal outcomes in type 2 diabetes. N Engl J Med. 2017;377(9):839-48.

52. Marso SP, Daniels GH, Brown-Frandsen K,et al. Liraglutide and cardiovascular outcomes in type 2 diabetes. N Engl J Med. 2016;375(4):311-22.
53. Marso SP, Bain SC, Consoli A, et al. Semaglutide and cardiovascular outcomes in patients with type 2 diabetes. N Engl J Med. 2016;375(19):1834-44.

54. Husain M, Birkenfeld AL, Donsmark M, et al. Oral semaglutide and cardiovascular outcomes in patients with type 2 diabetes. $\mathrm{N}$ Engl J Med. 2019;381(9):841-51.

55. Gerstein HC, Colhoun HM, Dagenais GR, et al. Dulaglutide and renal outcomes in type 2 diabetes: an exploratory analysis of the REWIND randomised, placebo-controlled trial. Lancet. 2019;394(10193):131-8.

56. Gerstein HC, Colhoun HM, Dagenais GR, et al. Dulaglutide and cardiovascular outcomes in type 2 diabetes (REWIND): a double-blind, randomised placebo-controlled trial. Lancet. 2019;394(10193): 121-30.

57. Tuttle KR, Lakshmanan MC, Rayner B, et al. Dulaglutide versus insulin glargine in patients with type 2 diabetes and moderate-to-severe chronic kidney disease (AWARD-7): a multicentre, open-label, randomised trial. Lancet Diabetes Endocrinol. 2018;6(8):605-17.

58. Bethel MA, Mentz RJ, Merrill P, et al. Microvascular and cardiovascular outcomes according to renal function in patients treated with once-weekly exenatide: Insights from the EXSCEL trial. Diabetes Care. 2020;43(2):446-52.

59. Muskiet MHA, Tonneijck L, Huang Y, et al. Lixisenatide and renal outcomes in patients with type 2 diabetes and acute coronary syndrome: an exploratory analysis of the ELIXA randomised, placebo-controlled trial. Lancet Diabetes Endocrinol. 2018;6(11):859-69.

60. Pfeffer MA, Claggett B, Diaz R, et al. Lixisenatide in patients with type 2 diabetes and acute coronary syndrome. N Engl J Med. 2015;373(23):2247-57.

61. Kidney Disease: Improving Global Outcomes (KDIGO) CKD Work Group. KDIGO 2012 clinical practice guideline for the evaluation and management of chronic kidney disease. Kidney Int Suppl. 2013;3:1-150. 